\title{
Fertilização de cobertura com boro e potássio na nutrição e produtividade da batata-doce
}

\author{
Fábio R Echer²; Júlio C Dominato²; José E Creste'; Diego H Santos² \\ ${ }^{1}$ UNOESTE-CCA, Campus II, Rod. Raposo Tavares, km 572, 19067-175 Presidente Prudente-SP; ${ }^{2}$ Mestrando em Agronomia; \\ fabioecher@gmail.com
}

\begin{abstract}
RESUMO
Os Latossolos e Argissolos apresentam elevada taxa de intemperização dos seus materiais constituintes, com pouca ou nenhuma reserva mineral de potássio (K) e normalmente, baixos teores de matéria orgânica do solo, principal fonte de boro (B) às plantas. $\mathrm{O}$ objetivo do trabalho foi avaliar a produtividade da cultura da batatadoce em resposta à combinação de doses de adubação potássica e boratada. $\mathrm{O}$ experimento foi conduzido entre os meses de agosto de 2007 e janeiro de 2008, em lavoura comercial de batata-doce, cv. Canadense, em Presidente Prudente-SP. O delineamento experimental utilizado foi de blocos casualizados, com três repetições, em esquema fatorial 4x4: doses de adubação potássica $(0 ; 50 ; 100$ e $200 \mathrm{~kg}$ ha $^{-1}$ de $\left.\mathrm{K}_{2} \mathrm{O}\right)$ e doses de adubação boratada $\left(0 ; 1 ; 2\right.$ e $3 \mathrm{~kg} \mathrm{ha}^{-1}$ de $\left.\mathrm{B}\right)$, ambas aplicadas em cobertura. Os tratamentos foram aplicados aos 62 dias após o plantio. A maior produtividade obtida foi de 27,7 t ha-1, com a combinação das doses de $2 \mathrm{~kg} \mathrm{ha}^{-1}$ de $\mathrm{B}$ aliada à aplicação de $200 \mathrm{~kg} \mathrm{ha}^{-1} \mathrm{de} \mathrm{K}_{2} \mathrm{O}$. O teor foliar de B aumentou conforme o aumento da dose de $\mathrm{B}$ e de $\mathrm{K}$. Doses de 1 e $3 \mathrm{~kg} \mathrm{ha}^{-1}$ de B não influenciaram o teor de $\mathrm{Mg}$ nas folhas, mas em doses de 0 e de $2 \mathrm{~kg} \mathrm{ha}^{-1}$ de $\mathrm{B}$ o teor de $\mathrm{Mg}$ apresentou comportamento quadrático em função do aumento da adubação potássica.
\end{abstract}

Palavras-chave: Ipomoea batatas, produção comercial, teor de nutrientes, adubação.

\begin{abstract}
Fertilization with boron and potassium on sweet potato nutrition and yield

Most of Brazilian soils have little or no mineral reserve of potassium and, usually low content of organic matter in the soil, the most important source of boron for the plants. In this work we evaluated the yield of sweet potato, cultivar Canadense, in response to the combination of different rates of potassium fertilization and boron fertilization. The research was carried out from August 2007 to January 2008, in Presidente Prudente, São Paulo State, Brazil. The experimental design consisted of randomized blocks in a factorial scheme $4 \times 4$, with three repetitions: rates of potassium fertilization $\left(0,50,100\right.$ and $200 \mathrm{~kg} \mathrm{ha}^{-1}$ of $\left.\mathrm{K}_{2} \mathrm{O}\right)$, and levels of boron fertilization $\left(0,1,2\right.$ and $3 \mathrm{~kg} \mathrm{ha}^{-1}$ of $\left.\mathrm{B}\right)$, both in side dressing. The treatments were applied 62 days after planting date. The maximum estimated yield was of $27.7 \mathrm{t} \mathrm{ha}^{-1}$, with combination of the rates of $2 \mathrm{~kg} \mathrm{ha}^{-1}$ of $\mathrm{B}$ allied to the application of $200 \mathrm{~kg} \mathrm{ha}^{-1}$ of $\mathrm{K}_{2} \mathrm{O}$. The foliar nutrient content of $\mathrm{B}$ increased with increasing rates of $\mathrm{B}$ and $\mathrm{K} .1$ and $3 \mathrm{~kg} \mathrm{ha}^{-1}$ of $\mathrm{B}$ rates did not influence the foliar content of $\mathrm{Mg}$, but with rates of 0 and $2 \mathrm{~kg} \mathrm{ha}^{-1}$ of $\mathrm{B}$ the $\mathrm{Mg}$ foliar content presented quadratic behavior in function of increasing $\mathrm{K}$ fertilization.
\end{abstract}

Keywords: Ipomoea batatas; marketable yield; nutrient content.

\section{(Recebido para publicação em 28 de maio de 2008; aceito em 22 de abril de 2009} (Received in May 28, 2008; accepted in April 22, 2009)

$\mathrm{O}$ s solos brasileiros, em sua grande maioria, são constituídos por Latossolos e Argissolos. Os mesmos apresentam elevada taxa de intemperização dos seus materiais constituintes, restando pouca ou nenhuma reserva mineral de nutrientes nas maiores frações, dominadas quase que exclusivamente por quartzo e outros materiais resistentes ao intemperismo (Meurer et al., 1996).

A matéria orgânica do solo constitui-se a principal fonte de boro disponível às plantas (Abreu, et al., 2007; Dechen \& Nachtigall, 2007). Assim, solos altamente intemperizados, especialmente os arenosos, em condições de alta pluviosidade, tendem a apresentar baixos teores de matéria orgânica e conseqüentemente baixo aporte de B (Dechen \& Nachtigall, 2007), o que pode ser minimizado com o acréscimo da adubação boratada nos programas de adubação das culturas.

Dentre os fatores que afetam a absorção de potássio, a morfologia do sistema radicular determina a sua absorção $\mathrm{e}$, conseqüentemente, influencia seu transporte na solução do solo em direção às raízes (Ernani et al., 2007). Sendo assim, à medida que o sistema radicular aumenta, resultando na exploração de maior volume de solo, aumenta também a absorção de K.

O K desempenha diversas funções na planta, destacando-se a ativação de enzimas; atua na fotossíntese e respiração, síntese de proteínas, carboidratos e da ATP; na regulação osmótica, na manutenção de água na planta por meio do controle da abertura e fechamento dos estômatos (Marschner, 1995). A de- ficiência de $\mathrm{K}$ origina frutos de menor tamanho e com menor intensidade de cor (Ernani et al., 2007).

Já o B compõe a membrana celular; atua no transporte de açúcares realizado pelo $\mathrm{K}$ via floema, participa da divisão, diferenciação e elongação celular e tem papel na fecundação e na germinação do grão-de-pólen. Aumenta a absorção de $\mathrm{P}, \mathrm{Cl}$ e $\mathrm{K}$ através do sistema radicular; inibe a formação de amido e atua no metabolismo e transporte de carboidratos até os órgãos de reserva (Malavolta et al.,1997). Além disso, os metabolismos do RNA e do AIA (Ácido Indol Acético) são mediados pelo B; participa ainda da respiração, da fixação de $\mathrm{N}_{2}$, e na diminuição da toxicidade de Al. A deficiência de B aumenta a queda de botões florais, flores e frutos em desenvolvimento, bem como é responsá- 
vel pelo insucesso do estabelecimento de sementes e de frutos (Kirkby \& Römheld, 2007).

As raízes tuberosas da batata-doce constituem o principal produto comercial da cultura, ricas em carboidratos, com grande demanda na alimentação humana, e elevado potencial para ração animal, produção industrial de farinha, amido e álcool (Clark \& Moyer, 1988).

A batata-doce chega a remover de 300 a $400 \mathrm{~kg} \mathrm{ha}^{-1}$ de $\mathrm{K}_{2} \mathrm{O}$ por meio da colheita das raízes tuberosas, para uma colheita de $30 \mathrm{t} \mathrm{ha}^{-1}$, podendo exaurir rapidamente as reservas dos solos, principalmente os mais arenosos (Potafos, 1990). Relatos na literatura indicam que para cada tonelada de tubérculos de batata-doce, são extraídas 66 gramas de B (Byju, 2007). Assim, para produtividades de $20 \mathrm{t} \mathrm{ha}^{-1}$, a exportação seria de $1,32 \mathrm{~kg} \mathrm{ha}^{-1}$ de B.

Em plantas deficientes em $\mathrm{K}$ ocorre intenso amarelecimento e necrose nas bordas entre as nervuras de folhas velhas; há uma diminuição da pigmentação roxa em folhas jovens e no ponteiro e os tubérculos têm a sua espessura diminuída (O’Sullivan et al., 1997). Os sintomas da deficiência de B em batatadoce caracterizam-se pelo engrossamento de folhas jovens que se enrolam para baixo; crescimento compacto devido à redução dos internódios, clorose mosqueada; redução de lóbulos e margens irregulares; morte do meristema apical; formação de raízes curtas, grossas e de tubérculos rachados; ocorre ainda a formação de bolhas na superfície do tubérculo; em casos mais severos as raízes laterais ficam curtas, altamente ramificadas e engrossadas (O’Sullivan et al., 1997). Há indicação que a presença do $\mathrm{H}_{3} \mathrm{BO}_{3}$ na adubação de solo aumenta o teor de K na planta, sendo que o inverso não ocorre.

Embora conhecida por sua rusticidade, tolerância à seca e sua sensibilidade a solos pobres, a batata-doce requer água e nutrientes suficientes para que haja um bom rendimento da cultura (Huaman, 1992).

Alguns trabalhos com adubação em batata-doce têm apresentado bons resultados em termos de produtividade, como os obtidos por Brito et al (2006) com doses de K; por Echer et al (2007) com a interação entre NxK; por Oliveira et al (2005a) e Oliveira et al (2006) com $\mathrm{N}$ e por Oliveira et al (2005b) com a aplicação de fósforo. Todavia, trabalhos que envolvam a aplicação de micronutrientes, são escassos.

Este trabalho teve por objetivo estudar a influência da combinação de níveis de adubação potássica e boratada sobre a nutrição e a produtividade da cultura da batata-doce, na região do Oeste Paulista, em Presidente Prudente-SP.

\section{MATERIAL E MÉTODOS}

O experimento foi conduzido entre os meses de agosto de 2007 e janeiro de 2008, em lavoura comercial de batata doce em Presidente Prudente-SP, definida pelas seguintes coordenadas geográficas: latitude $22^{\circ} 06 ' 50$ ' $S$ e longitude $51^{\circ} 27^{\prime} 32$ 'W, a uma altitude média de 406 m. Na Figura 1 estão os dados referentes às condições climáticas durante a condução do experimento.

O solo da área foi classificado como Argissolo Vermelho-Amarelo arenoso (Embrapa, 1999). De acordo com a análise de solo antes da instalação do experimento, este apresentou as características: $\mathrm{pH}\left(\mathrm{CaCl}_{2} 0,01 \mathrm{~mol} \mathrm{~L}^{-1}\right) 5,4 ; 10 \mathrm{~g} \mathrm{dm}^{-3}$ de $\mathrm{MO} ; 39 \mathrm{mg} \mathrm{dm}^{-3}$ de $\mathrm{P}_{\text {resina }} ; 15 \mathrm{mmol}_{\mathrm{c}}$ $\mathrm{dm}^{-3}$ de $\mathrm{H}+\mathrm{Al} ; 2,1 \mathrm{mmol} \mathrm{dm}^{-3}$ de $\mathrm{K} ; 19$ $\mathrm{mmol}_{\mathrm{c}} \mathrm{dm}^{-3}$ de Ca; $5 \mathrm{mmol}_{\mathrm{c}} \mathrm{dm}^{-3}$ de $\mathrm{Mg}$; 5,6 $\mathrm{mg} \mathrm{dm}^{-3}$ de $\mathrm{S} ; 26 \mathrm{mmol}_{\mathrm{c}} \mathrm{dm}^{-3}$ de SB; $41 \mathrm{mmol}_{\mathrm{c}} \mathrm{dm}^{-3}$ de CTC; saturação por bases de $63 \%$; 40,4 $\mathrm{mg} \mathrm{dm}^{-3}$ de $\mathrm{Mn} ; 19$ $\mathrm{mg} \mathrm{dm}^{-3}$ de Fe; $0,7 \mathrm{mg} \mathrm{dm}^{-3}$ de $\mathrm{Cu} ; 1,9 \mathrm{mg}$ $\mathrm{dm}^{-3}$ de Zn e $0,13 \mathrm{mg} \mathrm{dm}^{-3}$ de B.

O preparo do solo deu-se com duas arações pesadas, três gradagens leves e com a marcação de curvas de nível. As leiras foram demarcadas com espaçamento entre si de $0,90 \mathrm{~m}$. O plantio foi realizado em agosto de 2007, utilizando-se a cultivar Canadense. Utilizaram-se ramas coletadas na mesma propriedade. A adubação de plantio foi de $250 \mathrm{~kg} \mathrm{ha}^{-1}$ da fórmula NPK 4-30-10.

O delineamento experimental utilizado foi de blocos casualizados, com três repetições, em esquema fatorial 4x4, totalizando 16 tratamentos: doses de adubação potássica de $0,50,100$ e $200 \mathrm{~kg} \mathrm{ha}^{-1}$ de $\mathrm{K}_{2} \mathrm{O}$, fonte $\mathrm{KCl}$, e doses de adubação boratada com $0,1,2$ e $3 \mathrm{~kg} \mathrm{ha}^{-1} \mathrm{de} \mathrm{B}$, fonte $\mathrm{H}_{3} \mathrm{BO}_{3}$, ambas aplicadas em cobertura.
Cada parcela continha 50 plantas, em uma área de $20 \mathrm{~m}^{2}$, com dimensões de $5 \mathrm{x}$ 3,6 m, com quatro linhas de plantio. A área útil compreendeu as duas linhas centrais da parcela, totalizando $9 \mathrm{~m}^{2}$.

Os tratamentos foram aplicados em 18 de outubro de 2007, 62 dias após o plantio, e em 12 de dezembro de 2007 foram coletadas folhas para a realização das análises foliares, seguindo metodologia descrita em Malavolta et al. (1997). A colheita foi realizada em janeiro de 2008, aos 145 dias após o plantio. A produtividade comercial correspondeu ao peso das raízes de formato uniforme e lisas, com peso igual ou superior a $80 \mathrm{~g}$, conforme Embrapa (1995).

O estudo estatístico constou de análise de regressão, e foram ajustadas equações significativas até $5 \%$ de probabilidade pelo teste F que apresentaram os maiores coeficientes de determinação $\left(\mathrm{R}^{2}\right)$.

\section{RESULTADOS E DISCUSSÃO}

Na Figura 2 estão apresentadas as curvas de resposta da adubação potássica em combinação com as doses de boro aplicadas ao solo. Na ausência de adubação potássica, verificou-se incremento na produtividade de batatadoce conforme o aumento da dose de B. Isso indica que o aporte de B melhorou a produtividade, independentemente do acréscimo de $\mathrm{K}$ e, que o solo pode ter fornecido o mínimo suficiente para alcançar essas produtividades, já que o teor inicial de K no solo era de 2,1 mmol $\mathrm{dm}^{-3}$ e foi realizada uma adubação inicial com $250 \mathrm{~kg} \mathrm{ha}^{-1}$ da formula 4-30-10.

Quando não foi realizada a adubação boratada, observou-se resposta à adubação potássica até a dose de 138 $\mathrm{kg} \mathrm{ha}^{-1}$ de $\mathrm{K}_{2} \mathrm{O}$, com pico de produtividade de $21 \mathrm{t} \mathrm{ha}^{-1}$ (Figura 2). No entanto, quando a dose utilizada foi de $1 \mathrm{~kg} \mathrm{ha}^{-1}$ de $\mathrm{B}$, a máxima produtividade de $22,5 \mathrm{t}$ $\mathrm{ha}^{-1}$, foi obtida com a dose de $103,96 \mathrm{~kg}$ $\mathrm{ha}^{-1}$ de $\mathrm{K}_{2} \mathrm{O}$. Esses dados sugerem um efeito sinérgico entre o $\mathrm{K}$ e o $\mathrm{B}$, pois a adição de um potencializou a utilização de outro.

A maior produtividade obtida foi de $27,7 \mathrm{t} \mathrm{ha}^{-1}$, com a utilização de $2 \mathrm{~kg} \mathrm{ha}^{-1}$ de $\mathrm{B}$, aliada à aplicação de $200 \mathrm{~kg} \mathrm{ha}^{-1} \mathrm{de}$ 
$\mathrm{K}_{2} \mathrm{O}$, conforme a Figura 2. Trabalhos que envolvam a interação entre K e B são escassos na literatura. No Brasil não é diferente, pois são raros os resultados de pesquisa da interação entre K e B na cultura da batata-doce, entretanto em alguns manuais de adubação, verificase a inclusão da adubação boratada (Silva et al., 2002; Reis et al.,1996). Entretanto, em estudos desenvolvidos por Davis et al. (2003) na cultura do tomate demonstraram que o aumento do fornecimento de $\mathrm{B}$ aumentou a absorção e a translocação de K; o mesmo foi verificado por Schon \& Blevins (1990) em soja.

Alguns autores têm estudado o efeito isolado do $\mathrm{K}$ sobre a produtividade da cultura da batata-doce; assim, Brito et al (2006) estudando doses de $\mathrm{K}_{2} \mathrm{O}$ na cultura da batata doce em um solo de textura franco-arenosa obtiveram produtividade comercial de $8,4 \mathrm{t} \mathrm{ha}^{-1}$ com a dose de $163 \mathrm{~kg} \mathrm{ha}^{-1}$ de $\mathrm{K}_{2} \mathrm{O}$.

Outros trabalhos que envolvam a interação do $\mathrm{K}$ com outros nutrientes são incomuns. No entanto, Echer et al. (2007) estudaram a resposta da interação entre doses de $\mathrm{N}$ e de $\mathrm{K}$, e verificaram que a utilização de $120 \mathrm{~kg} \mathrm{ha}^{-1}$ de $\mathrm{K}_{2} \mathrm{O}$ em combinação com $100 \mathrm{~kg} \mathrm{ha}^{-1}$ de $\mathrm{N}$ foram responsáveis pela produtividade máxima de 23,44 tha ${ }^{-1}$.

Por outro lado, autores de outros países como Granberry et al., (2007) recomendam a utilização de $1,12 \mathrm{~kg} \mathrm{ha}^{-1} \mathrm{de}$ $\mathrm{B}$ e de $30-180 \mathrm{~kg} \mathrm{ha}^{-1}$ de $\mathrm{K}_{2} \mathrm{O}$ para a produção de batata-doce nos EUA. Já Swiader (2007), também nos EUA, recomenda a utilização de 0,5 a $3,2 \mathrm{~kg} \mathrm{ha}^{-1} \mathrm{de}$ $\mathrm{B}$, sendo que as doses mais elevadas devem ser aplicadas em solos com baixo teor de matéria orgânica, solos arenosos e altamente intemperizados.

No Brasil, Silva et al. (2002) indicam a utilização de $60 \mathrm{~kg} \mathrm{ha}^{-1}$ de $\mathrm{K}_{2} \mathrm{O}$ em solos com teor alto de $\mathrm{K}$; e de 1 a $2 \mathrm{~kg} \mathrm{ha}^{-1}$ de $\mathrm{B}$ em solos com baixa fertilidade, como é o caso dos solos da região do Cerrado brasileiro. Por outro lado, Reis et al (1996) indica a utilização de 0,5 a $1 \mathrm{~kg} \mathrm{ha}^{-1}$ de B em solos com baixos teores desse micronutriente.

Os resultados obtidos contrastam como a recomendação proposta por Filgueira (2003) que preconiza a adubação potássica na cultura da batata-doce que varia de 90-120 $\mathrm{kg} \mathrm{ha}^{-1}$ de $\mathrm{K}_{2} \mathrm{O}$, e

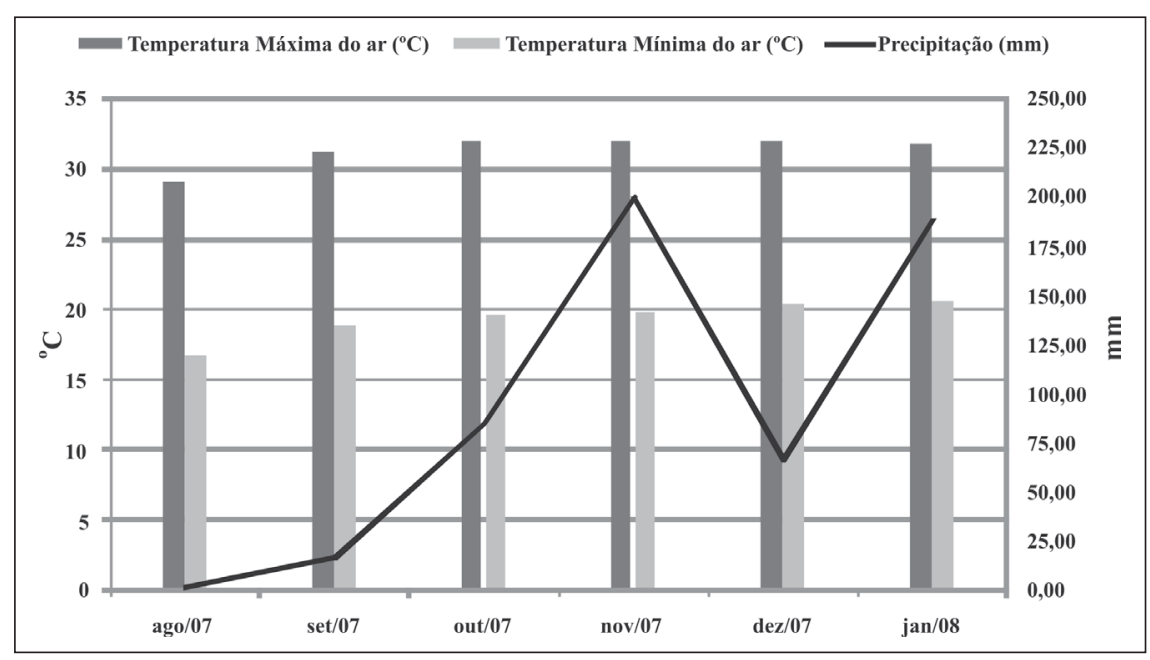

Figura 1. Temperatura máxima e mínima do ar e precipitação durante a condução do experimento (maximum and minimum air temperature and precipitation during the conduction of the research). Presidente Prudente, UNOESTE, 2007/2008.

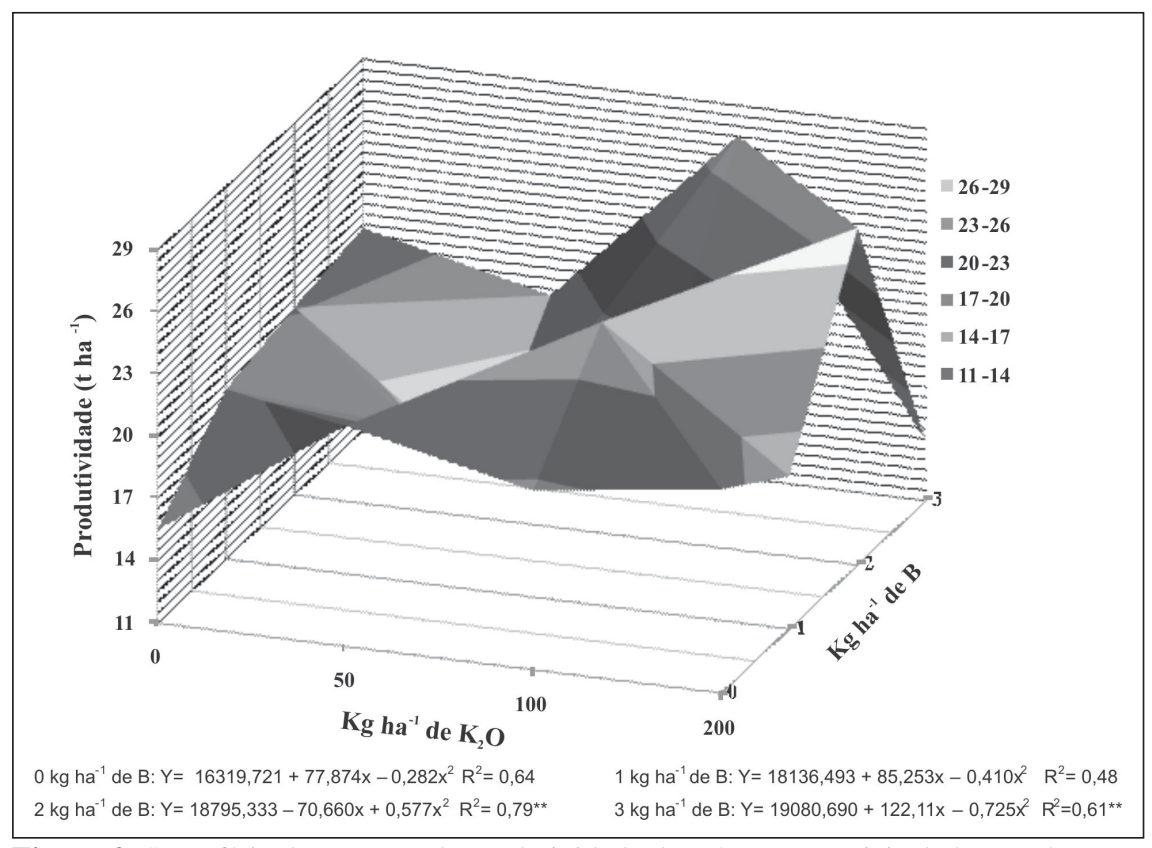

Figura 2. Superfície de resposta da produtividade de raízes comerciais de batata-doce em função das doses de adubo com potássio e boro (commercial yield of sweet potato roots ,in function of the fertilizer rates with potassium and boron). Presidente Prudente, UNOESTE, 2007/2008.

com Monteiro \& Peressin (1997) que recomendam a adubação com $60 \mathrm{~kg} \mathrm{ha}^{-1}$ de $\mathrm{K}_{2} \mathrm{O}$ em solos com altos teores desse nutriente.

De acordo com a análise química, apenas os teores foliares de $\mathrm{Mg}$ e B apresentaram diferença significativa. Na Figura 3 estão dispostos os resultados do teor foliar de B em função das doses de B e de K. Observou-se que, na ausência da adubação potássica, o teor de B nas folhas da batata-doce apresentou com- portamento quadrático, sendo que a menor concentração ocorreu na dose de $1 \mathrm{~kg} \mathrm{ha}^{-1} \mathrm{de}$ B. Para as demais doses de $\mathrm{K}_{2} \mathrm{O}$, observou-se comportamento linear positivo conforme o aumento da dose de B. O maior teor foliar de B obtido foi de $115 \mathrm{mg} \mathrm{kg}^{-1}$, com a combinação das doses de $200 \mathrm{~kg} \mathrm{ha}^{-1}$ de $\mathrm{K}_{2} \mathrm{O}$ com $3 \mathrm{~kg}$ ha $^{-1}$ de $\mathrm{B}$, acima dos teores adequados para a cultura da batata-doce indicados por Lorenzi et al. (1997), que varia de 25$75 \mathrm{mg} \mathrm{kg}^{-1}$. No entato, O'Sullivan et al. 


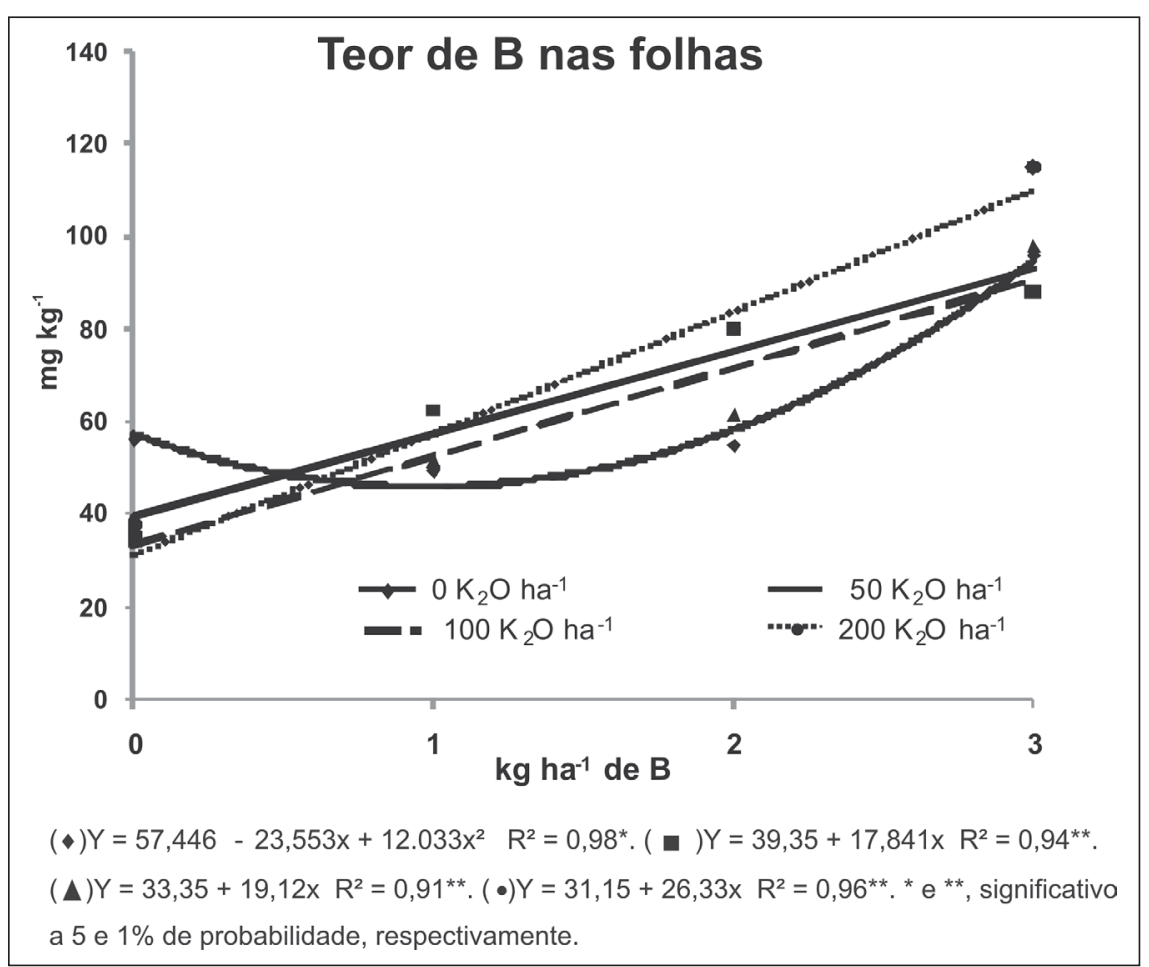

Figura 3. Teores de B nas folhas em função das doses de potássio e de boro (foliar contento f B in function of the rates of potassium and boron). Presidente Prudente, UNOESTE, 2007/2008.

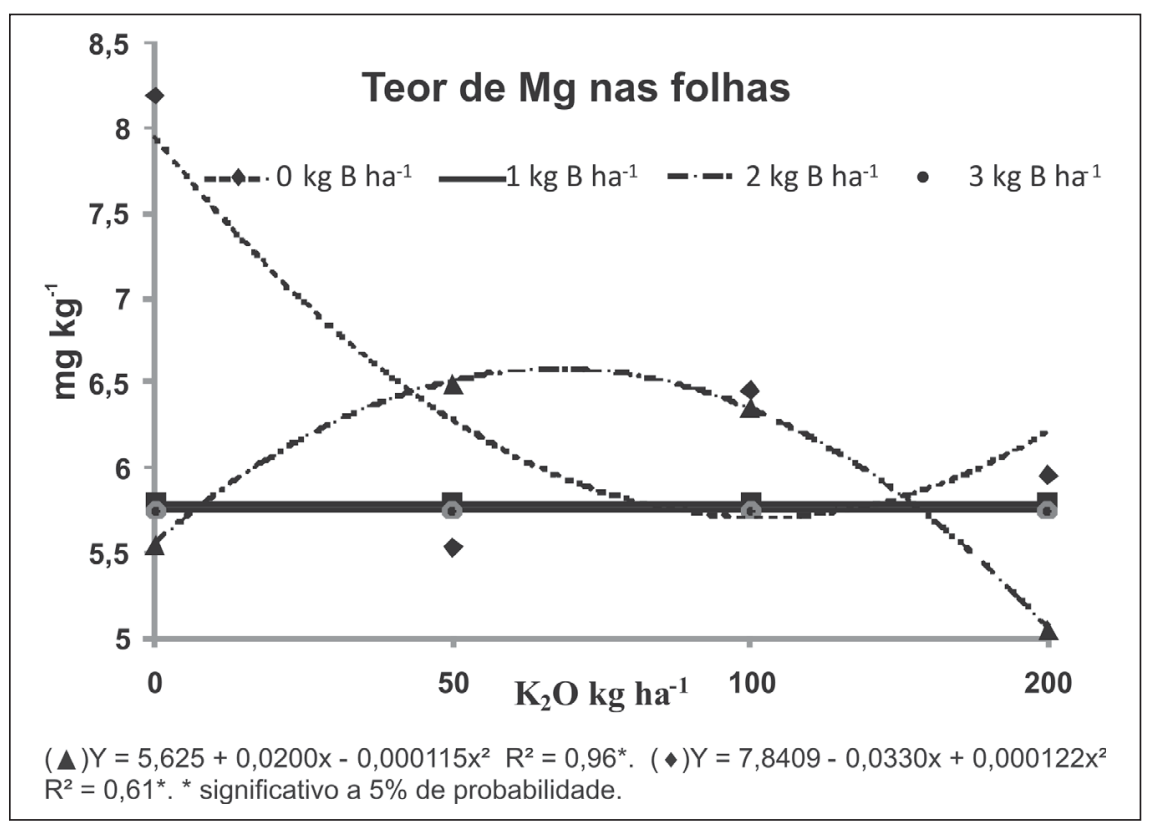

Figura 4. Teores de Mg nas folhas em função das doses de potássio e de boro. Presidente Prudente, UNOESTE, 2007/2008.

(1997) relatam que os teores foliares adequados de B variam de 50-200 $\mathrm{mg} \mathrm{kg}^{-1}$, ocorrendo problemas de fitotoxidez em concentrações superiores a $220 \mathrm{mg} \mathrm{kg}^{-1}$.

$\mathrm{O}$ teor de $\mathrm{Mg}$ nas folhas de batatadoce não variou com o aumento da adubação potássica em função da aplica- folhas de batata-doce obtido na ausência de K. Quando foram aplicados $2 \mathrm{~kg}$ $\mathrm{ha}^{-1}$ de $\mathrm{B}$, a resposta também foi quadrática, e o teor máximo de $\mathrm{Mg}$ nas folhas foi obtido com a aplicação de 87 $\mathrm{kg} \mathrm{ha}^{-1}$ de $\mathrm{K}_{2} \mathrm{O}$.

Esses valores estão de acordo com os teores considerados como adequados por Lorenzi et al., (1997) que em folhas de batata-doce é de 3-12 $\mathrm{g} \mathrm{kg}^{-1}$. O'Sullivan et al.(1997) relatam que foram observados sintomas de deficiência em lavouras de batata-doce em países como Uganda e Austrália, e estes foram associados a concentrações de $\mathrm{Mg}$ nas folhas de 2,9$3,7 \mathrm{~g} \mathrm{~kg}^{-1}$ e nos Estados Unidos observou-se deficiência de $\mathrm{Mg}$ com teores foliares de $4 \mathrm{~g} \mathrm{~kg}^{-1}$.

Com base nos resultados obtidos pode-se concluir que a máxima produtividade obtida foi de $27,7 \mathrm{tha}^{-1}$, com a combinação das doses em cobertura de $2 \mathrm{~kg} \mathrm{ha}^{-1}$ de $\mathrm{B}$ aliada à aplicação de 200 $\mathrm{kg} \mathrm{ha}^{-1}$ de $\mathrm{K}_{2} \mathrm{O}$. O teor foliar de B aumentou conforme o aumento da dose de $\mathrm{B}$ e de $\mathrm{K}$, e o teor de $\mathrm{Mg}$ nas folhas foi influenciado pela combinação das doses de B e de K.

\section{AGRADECIMENTOS}

Ao proprietário e aos funcionários do Rancho Ebenezer, Marcos e Ricardo por terem cedido a área para realização do experimento e pela colaboração na condução do mesmo.

\section{REFERÊNCIAS}

ABREU CA; LOPES AS; SANTOS G. 2007. Micronutrientes. In: NOVAIS RF; ALVAREZ VVH; BARROS NF; FONTES RLF; CANTARUTTI RB; NEVES JCL (eds). Fertilidade do Solo. Viçosa: SBCS/ UFV. p. 645-736

BRITO CH; OLIVEIRA AP; ALVES AU; DORNELES CSM; SANTOS JF; NÓBREGA JPR. 2006. Produtividade da batata-doce em função de doses de $\mathrm{K}_{2} \mathrm{O}$ em solo arenoso. Horticultura Brasileira 24: 320-323.

BYJU G. 200728 de março. Sweet potato. Disponível em: http://www.ctcri.org/ byju.htmhttp.

CLARK CA; MOYER JW. 1988. Compendium of sweet potato diseases. Saint Paul: APS Press. 74p.

DAVIS JM; SANDERS DC; NELSON PV; LENGNICK L; SPERRY WJ. 2003. Boron improves growth, yield, quality and nutrient content of tomato. Journal of the American Society of Horticultural Science, 128: 441-446. 
DECHEN AR; NACHTIGALL GR. 2007. Elementos requeridos à nutrição de plantas. In: NOVAIS RF; ALVAREZ VVH; BARROS NF; FONTES RLF; CANTARUTTI RB; NEVES JCL (eds). Fertilidade do Solo. Viçosa: SBCS/UFV. p. 92-132.

ECHER FR; FOLONI JSS; TIRITAN CS; SANTOS DH; CORTE A. 2007. Adubação nitrogenada e potássica de cobertura na Batata-doce. In: Encontro de Ensino, Pesquisa e Extensão (ENEPE). Anais... Presidente Prudente: CD-ROM.

EMBRAPA. Centro Nacional de Pesquisa de Solos. 1999. Sistema Brasileiro de classificação de solos. Brasília: EmbrapaSPI, Embrapa-CNPS. 412 p.

EMBRAPA. 1995. Centro Nacional de Pesquisa de Hortaliças. Cultivo da batata-doce (Ipomoea batatas (L.) Lam). 3. ed. Brasília: Ministério da Agricultura, do Abastecimento e Reforma Agrária, (EMBRAPA-CNPH. Instruções Técnicas, 7). 18p.

ERNANI PR; ALMEIDA JA; SANTOS FC. 2007. Potássio. In: NOVAIS RF; ALVAREZ VH; BARROS NF; FONTES RLF; CANTARUTTI RB; NEVES JCL. Fertilidade do solo. Viçosa: SBCS/UFV. p. 551-594

FILGUEIRA FAR. 2003. Novo manual de olericultura: agrotecnologia moderna na produção e comercialização de hortaliças. 2. ed. Viçosa: UFV. 412 p.

GRANBERRY DM; KELLEY WT; BOYHAN G. 2007. Sweet potato: commercial vegetable production. The University of Georgia College of Agricultural and Environmental Sciences and the U.S. Department of Agriculture cooperating. Circular 677.

HUAMAN Z. 1992. Systemic botany and morphology of the sweetpotato plant. Technical Information Bulletin 25. International Potato Centre, Lima, Peru. $22 \mathrm{p}$.
KIRKBY EA; RÖMHELD V. 2007. Micronutrientes na fisiologia de plantas: funções, absorção e mobilidade. Tradução: Suzana Oellers Ferreira. Encarte Técnico. Informações Agronômicas $\mathrm{n}^{\circ} 118$.

LORENZI JO; MONTEIRO DA; MIRANDA FILHO HS. 1997. Raízes e tubérculos. In: RAIJ BV; CANTARELLA H; QUAGGIO JA; FURLANI AMC. Recomendações de adubação e calagem para o Estado de São Paulo. 2 ed. p. 221-230 (Boletim Técnico 100)

MALAVOLTA E; VITTI GC; OLIVEIRA SA. 1997. Avaliação do estado nutricional das plantas: princípios e aplicações. Piracicaba: Potafós, 201p.

MARSCHNER H. 1995. Mineral nutrition of higher plants. London: Academic Press. $889 \mathrm{p}$.

MEURER EJ; KÄMPF N; ANGHINONI I. 1996. Fontes potenciais de potássio em alguns solos do Rio Grande do Sul. Revista Brasileira de Ciências do Solo. 20: 41-47.

MONTEIRO DA; PERESSIN VA. 1997. Batatadoce e Cará. In: RAIJ B; CANTARELLA H; QUAGGIO JA; FURLANI AMC (Eds). Recomendações de adubação e calagem para o Estado de São Paulo. 2 ed. Campinas: Instituto Agronômico/Fundação IAC, 285p. (Boletim técnico 100).

OLIVEIRA AP; MOURA MF; NOGUEIRA DH; CHAGAS NG; BRAZ MSS; OLIVEIRA MRT; BARBOSA JA. 2006. Produção de raízes de batata-doce em função do uso de doses de $N$ aplicadas no solo e via foliar. Horticultura Brasileira 24: 279-282.

OLIVEIRA AP; OLVEIRA MRT; BARBOSA JA; SILVA GG; NOGUEIRA DH; MOURA MF; BRAZ MSS. 2005. Rendimento e qualidade de raízes de batata-doce adubada com níveis de uréia. Horticultura Brasileira 23: 925-928.
OLIVEIRA AP; SILVA JEL; PEREIRA WE; BARBOSA LJN. 2005. Produção da batatadoce em função de doses de $\mathrm{P}_{2} \mathrm{O}_{5}$ em dois sistemas de plantio. Horticultura Brasileira 23: 768-772.

O'SULLIVAN JN; ASHER CJ; BLAMEY FPC. 1997. Nutrient disorders of sweet potato. ACIAR, Monograph $\mathrm{n}^{\circ}$. 48, Australian Centre for International Agricultural Research, Canberra. 136 p.

POTAFOS. 1990. Associação brasileira para pesquisa da potassa e do fosfato. Potássio: necessidade e uso na agricultura moderna. $45 \mathrm{p}$.

REIS MS; SOUZA RJ; CECÍLIO FILHO AB. 1996. A cultura da batata-doce (Ipomoea batatas (L) LAM). Lavras: UFLA. 19p. (Boletim Técnico).

SCHON MK; BLEVINS DG. 1990. Foliar boron applications increase the final number of branches and pools on branches of fieldgrown soybeans. Plant Physiology 92: 602607.

SILVA JBC; LOPES CA; MAGALHÃES JS. 2002. Cultura da batata-doce. In: CEREDA MP; Agricultura: Tuberosas amiláceas latino americanas, São Paulo: Cargill, 2: 449-503.

SWIADER JM. 2007, 28 de março. Micronutrient fertilizer recommendations for commercial and home-garden vegetables. Vegetable crops. Plant Nutrition and Soil Fertility Department of Natural Resources \& Environmental Sciences. Disponível em: <http://www.nres.uiuc.edu/ uploads/files/extension/hfs/ MicroFertRec.pdf> 